\title{
蝗虫の生化學的研究 (第二報)
}

市川親文

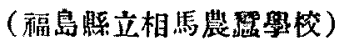

昭和 11 年 2 月 3 日受理

\section{1. 緒言}

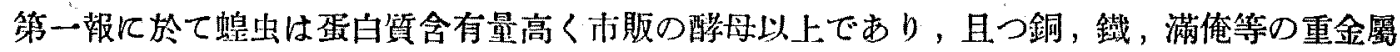
を念有主る事が，食品として使用され得ることを書いた。

本報には稳の成長と共に蝗虫の化學的成分が如何に變り行くか，取敢へず一般成分並びに無 僟成分の檢定を行つた成續を訅して，乙てに第二報とする次第である。

\section{2. 貝 驗 資 料}

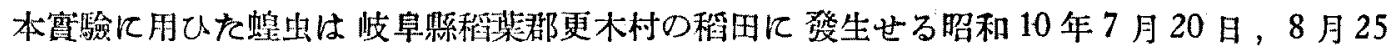
日，9月30日の三包採集したるもので，遖ちにクロロホルムで殺し，てれを日光乾燥せしも

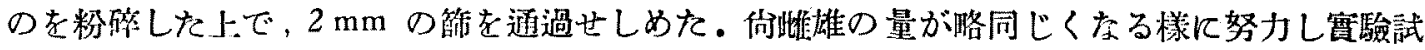
料とした。

\section{3. 各成分の定量法}

各成分の定量法は第一報に記载せし如くした。

\section{4. 贯 驗 成 績}

昭和10年 7 月20日，8月25日，9月30日に探集した缐虫の化學的分析成績は次の样である。

第一表 7 月20日採集の部

\begin{tabular}{|c|c|c|c|c|}
\hline & 分 事 項 & 生螅虫百分中 & 螑灰分 中 & 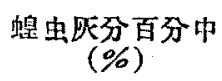 \\
\hline & 水 分 & 70.250 & -- & - \\
\hline & Total $N$ & 3.270 & $\ldots$ & - \\
\hline & 戻 分 & 1.448 & 4.867 & - \\
\hline & $\mathrm{SiO}_{2}$ & 0.230 & 0.774 & 15.895 \\
\hline & $\mathrm{Al}_{2} \mathrm{O}_{3}$ & 0.029 & 0.097 & 1.993 \\
\hline & $\mathrm{Fe}_{2} \mathrm{O}_{3}$ & 0.011 & 0.036 & 0.738 \\
\hline & $\mathrm{CaO}$ & 0.015 & 0.047 & 1.015 \\
\hline & $\mathrm{MgO}$ & 0.059 & 0.199 & 4.095 \\
\hline & $\mathrm{K}_{2} \mathrm{O}$ & 0.303 & 1.020 & 20.951 \\
\hline & $\mathrm{Na}_{2} \mathrm{O}$ & 0.253 & 0.849 & 17.440 \\
\hline & $\mathrm{P}_{2} \mathrm{O}_{5}$ & 0.524 & 1.762 & 36.203 \\
\hline & $\mathrm{SO}_{3}$ & 0.009 & 0.030 & 0.617 \\
\hline & $\mathrm{MnO}$ & 0.0021 & 0.007 & 0.138 \\
\hline & $\mathrm{TiO}$ & 0.001 & 0.004 & 0.088 \\
\hline & $\mathrm{CuO}$ & 0.0021 & 0.007 & 0.143 \\
\hline
\end{tabular}


第二表 8 月25日採集の部

\begin{tabular}{|c|c|c|c|}
\hline 成 分 事 項 & 生蝊虫百分中 & $\begin{array}{c}\text { 螅虫矦分中 } \\
(\%)\end{array}$ & 蛒蛎分百分中 \\
\hline 水 分 & 68.030 & - & - \\
\hline Total $N$ & 3.597 & $\underline{-}$ & - \\
\hline 死 分 & 1.954 & 6.113 & - \\
\hline $\mathrm{SiO}_{2}$ & 0.269 & 0.841 & 13.762 \\
\hline $\mathrm{AJ}_{2} \mathrm{O}_{3}$ & 0.035 & 0.109 & 1.784 \\
\hline $\mathrm{Fe}_{2} \mathrm{O}_{3}$ & 0.022 & 0.069 & 1.133 \\
\hline - $\mathrm{CaO}$ & 0.012 & 0.036 & 0.587 \\
\hline $\mathrm{MgO}$ & 0.055 & 0.171 & 2.798 \\
\hline $\mathrm{K}_{2} \mathrm{O}$ & 0.461 & 1.441 & 23.580 \\
\hline $\mathrm{Na}_{2} \mathrm{O}$ & 0.395 & 1.234 & 20.194 \\
\hline $\mathrm{P}_{2} \mathrm{O}_{5}$ & 0.667 & 2.085 & 34.113 \\
\hline $\mathrm{SO}_{3}$ & 0.018 & 0.057 & 0.940 \\
\hline $\mathrm{MnO}$ & 0.004 & 0.012 & 0.203 \\
\hline $\mathrm{TiO}_{2}$ & 0.003 & 0.008 & 0.132 \\
\hline $\mathrm{CuO}$ & 0.004 & 0.014 & 0.229 \\
\hline
\end{tabular}

第三表 9 月30日採箱の部

\begin{tabular}{|c|c|c|c|}
\hline 成 分 事 項 & 生蝗虫百分中 & 缐虫炏分中 & 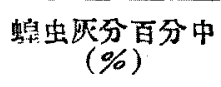 \\
\hline 水 分 & 67.930 & - & - \\
\hline Total N & 3.629 & - & - \\
\hline 兏 分 & 1.815 & 5.660 & - \\
\hline $\mathrm{SiO}_{2}$ & 0.298 & 0.928 & 16.400 \\
\hline $\mathrm{Al}_{2} \mathrm{O}_{3}$ & 0.040 & 0.124 & 2.195 \\
\hline $\mathrm{Fe}_{2} \mathrm{O}_{3}$ & 0.001 & 0.033 & 0.576 \\
\hline $\mathrm{CaO}$ & 0.002 & 0.051 & 0.896 \\
\hline $\mathrm{MgO}$ & 0.040 & 0.124 & 2.195 \\
\hline $\mathrm{K}_{2} \mathrm{O}$ & 0.343 & 1.070 & 18.912 \\
\hline $\mathrm{Na}_{2} \mathrm{O}$ & 0.293 & 0.913 & 16.124 \\
\hline $\mathrm{P}_{2} \mathrm{O}_{5}$ & 0.736 & 2.294 & 40.529 \\
\hline $\mathrm{SO}_{3}$ & 0.011 & 0.035 & 0.625 \\
\hline $\mathrm{MnO}$ & 0.002 & 0.007 & 0.132 \\
\hline $\mathrm{TiO}_{2}$ & 0.002 & 0.006 & 0.105 \\
\hline $\mathrm{CuO}$ & 0.004 & 0.011 & 0.200 \\
\hline
\end{tabular}

第四表 三回探集成分の比較

\begin{tabular}{|c|c|c|c|}
\hline 成 分 事 項 & $\begin{array}{c}7 \text { 月 } 20 \text { 日探集 } \\
\text { 成分 }(\%)\end{array}$ & $\begin{array}{c}8 \text { 月 } 25 \text { 日探集 } \\
\text { 成分 }(\%)\end{array}$ & $\begin{array}{c}9 \text { 月 } 30 \text { 日探集 } \\
\text { 成分 }(\%)\end{array}$ \\
\hline 水 分 & 70.250 & 68.030 & 67.930 \\
\hline
\end{tabular}




\begin{tabular}{l|r|r|r} 
Total N & 10.813 & 11.250 & 11.316 \\
灰分 & 4.867 & 6.113 & 5.660 \\
& & & \\
$\mathrm{SiO}_{2}$ & 15.895 & 13.762 & 16.400 \\
$\mathrm{Al}_{2} \mathrm{O}_{3}$ & 1.993 & 1.784 & 2.195 \\
$\mathrm{Fe}_{2} \mathrm{O}_{3}$ & 0.738 & 1.133 & 0.576 \\
$\mathrm{CaO}$ & 1.015 & 0.587 & 0.896 \\
$\mathrm{MgO}$ & 4.095 & 2.798 & 2.196 \\
$\mathrm{~K}_{2} \mathrm{O}$ & 20.951 & 23.580 & 18.912 \\
$\mathrm{Na}_{2} \mathrm{O}$ & 17.440 & 20.194 & 16.124 \\
$\mathrm{P}_{2} \mathrm{O}_{5}$ & 36.203 & 34.113 & 40.529 \\
$\mathrm{SO}_{3}$ & 0.617 & 0.940 & 0.625 \\
$\mathrm{MnO}$ & 0.138 & 0.203 & 0.132 \\
$\mathrm{TiO}_{2}$ & 0.088 & 0.132 & 0.105 \\
$\mathrm{CuO}^{\mathrm{H} O}$ & 0.143 & 0.229 & 0.200 \\
其の他 & 0.684 & 0.545 & 1.110 \\
\hline
\end{tabular}

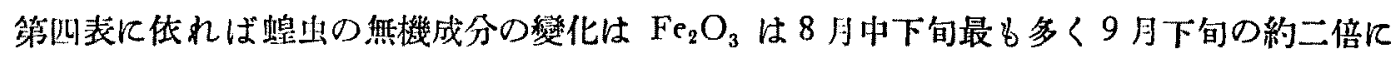
及び， $\mathrm{CaO}$ は 7 月上中旬最も多く, 8 月中下旬の約二倍に及べり。

$\mathrm{MgO}$ \& 7 月上中旬最多多く成長し行くに連れて減少し，9月下旬には 7 月上中旬の約二分 の一长至るを見る。

$\mathrm{K}_{2} \mathrm{O}$ 及 $\mathrm{Na}_{2} \mathrm{O}$ は 8 月中下旬最子多く，9 日下旬には 7 月中下旬より 減少するを見る。

$\mathrm{P}_{2} \mathrm{O}_{5}$ は 8 月中下旬最当少なく, 7 月中下旬上り9 月下旬は增加し, $\mathrm{SO}_{3}$ は 9 月小下旬と 9 月下旬之大差なく 8 月下旬最多多心。

$\mathrm{MnO}, \mathrm{TiO}_{2}, \mathrm{CuO}$ は 8 月下旬最も多く，7 月中下的と 9 月下旬とは大惹ないととを見る。

\section{5. 䄼括}

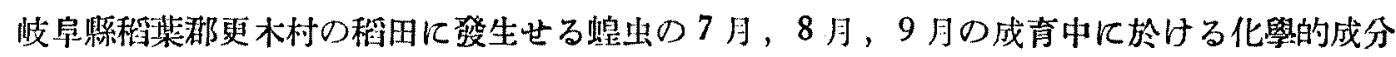
の變移に就いての研究の結果老報告した。

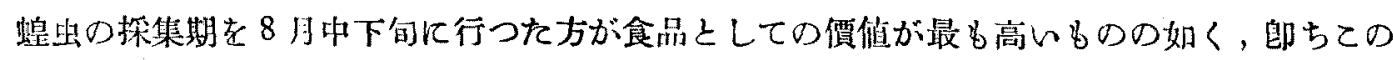
時期に稻に大害を與へるものと考へる。それで蝗出の探集期を 8 月中に行ふを得策の如し.

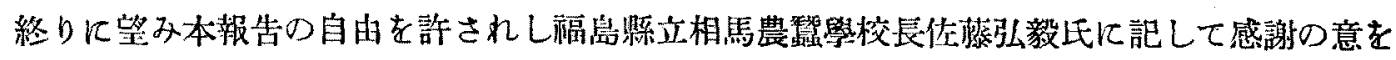
表与。 